\title{
Evaluation of shear bond strength and adhesive remnant index of orthodontic brackets bonded directly or indirectly with adhesive resin cements to bovine enamel
}

\begin{abstract}
The aim of this study was to evaluate differences in shear bond strength and in Adhesive Remnant Index using direct and indirect bonding techniques with two different resin cements. A total of 64 cow mandibular incisors were analyzed. Inclusion criteria were: intact buccal surfaces, no carious lesions, recent extraction, proper preparation and conservation. Elements were extracted, immersed in a $0.1 \%$ thymol solution and secured in cold resin. The material tested were Transbond (Unitek/3M, Monrovia, Calif) and Kuraray (Kuraray Medical, Tokyo, Japan). Teeth were divided in four groups: 1. Direct technique+Transbond; 2. Direct technique + Kurasper; 3. Indirect technique + Transbond; 4. Indirect technique+Kurasper. Upper right central incisor brackets were used in all groups and bonded directly or indirectly; Samples were tested for ARI and shear bond strength with a load cell of $5 \mathrm{KN}$. The two-way ANOVA test showed no significant difference for bonding technique $(\mathrm{p}=0.9606)$, composite cement used $(\mathrm{p}=0.1653)$ or interaction between these two variables $(\mathrm{p}=0.6077)$. The Chi-square test showed no significant difference in failure sites (ARI) in all groups ( $\mathrm{p}=0.185)$. There is no significant difference in adhesion force and in failure sites between direct and indirect techniques, with both cements.
\end{abstract}

Keywords: shear bond strength, ari index, indirect bonding technique
Volume 8 Issue 3 - 2017

\author{
Enrica Tessore, Laura Mazzotta, Arturo \\ Fortini \\ Department of Orthodontics, University of Cagliari, Italy
}

Correspondence: Laura Mazzotta, Department of Orthodontics, University of Cagliari,Via Zara 37-2, I6I45, Genova, Italy, Email laura.mazzotta@ymail.com

Received:September 26, 2017| Published: September 28, 2017

\section{Introduction}

The indirect bonding process was first described by Silverman and Cohen. ${ }^{1,2}$ in 1972. Since then, several different techniques for indirect bonding have been proposed, with different bracket preparation (standard or individualized), different types of transfer (single or jigs or full arches) and different materials (acrylic resin, silicon, thermoformed material). ${ }^{3-5}$ The indirect bonding technique offers several advantages over the direct technique, ${ }^{6}$ chair time saving, greater comfort for the patient, ${ }^{7,8}$ more precise bracket positioning, ${ }^{9,10}$ less need for repositioning during treatment (even with less experienced operators), ${ }^{11-13}$ less stress for the dentist and less accumulation of composite cement around the base of the brackets..$^{14,15}$ This, consequently, decreases the formation of plaque and calculus during orthodontic treatment. ${ }^{16}$ However, the indirect technique presents some disadvantages such as the need for additional impressions, the increase of lab time and costs and the possibility of having an adhesive overflow into the gingival sulcus. ${ }^{17}$ It has been debated that the direct bonding technique may have increased bond strength as the bracket bases fit closer to the tooth surfaces, leading to fewer detachments during treatment. ${ }^{4}$ In vitro. ${ }^{18,19}$ and in vivo studies. ${ }^{20,21}$ have been conducted to compare shear bond strength showing similar results; only one study reported significantly lower adhesion values. ${ }^{22}$ However, the materials tested in that study included a self-etching primer and a total-etching primer. Materials play a key role in shear bond strength: previous studies on dental cements have shown that many features of composites, including hardness, tensile and compressive strength, and flexural modulus may vary when different bonding technique or curing modes are used. Indeed, polymerization shrinkage of the composite material may cause gaps between the adhesive and the enamel surface and lead to microleakage, thus facilitating detachment or the formation of white spot lesions under the bracket. ${ }^{23}$ In this study, we aimed to analyze whether there exists a significant difference in shear bond strength and microleakage formation using direct and indirect bonding techniques with two different resin cements.

\section{Materials and methods}

A total of 64 cow mandibular incisors were analyzed. The inclusion criteria were: intact buccal surfaces, absence of enamel fracture lines, absence of carious lesions, recent extraction, proper preparation and conservation. Teeth that presented enamel defects, dehydration or that had not been stored properly were excluded. Teeth were extracted; soft tissue residues were removed with manual curettage (Figure 1). All elements were then immersed for one week in a $0.1 \%$ solution (weight / volume) of thymol. Teeth were secured individually in metal rings (diameter $15 \mathrm{~mm}$ ) with cold resin (Leocryl; Leone, Sesto Fiorentino, Italy); the tooth buccal face was placed parallel to the detachment force (Figure 2). Buccal faces were cleansed for 10 seconds with a mix of water and aluminum oxide (50micron) with a rubber polishing bur mounted on a contrangle, ${ }^{24}$ washed and dried (Figure 3). For this study, upper right central incisor brackets were used, with a 0.022 x 0.028 slot (D.B. STEP system 2.0® Leone, Firenze) and a base surface of $14 \mathrm{~mm}^{2}$. The adhesion procedure was performed by a single operator. The material tested were two light-curing composite cements used with the etching technique (orthophosphoric acid); each composite was used with the adhesive and the etchant recommended by the manufacturer: 


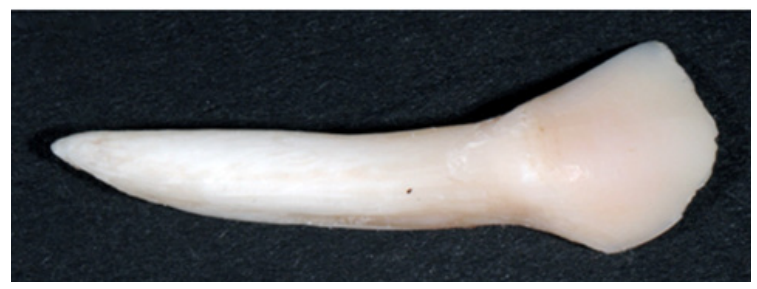

Figure I Extracted cow mandibular incisor; after removal of all soft tissue residues with manual curettage.

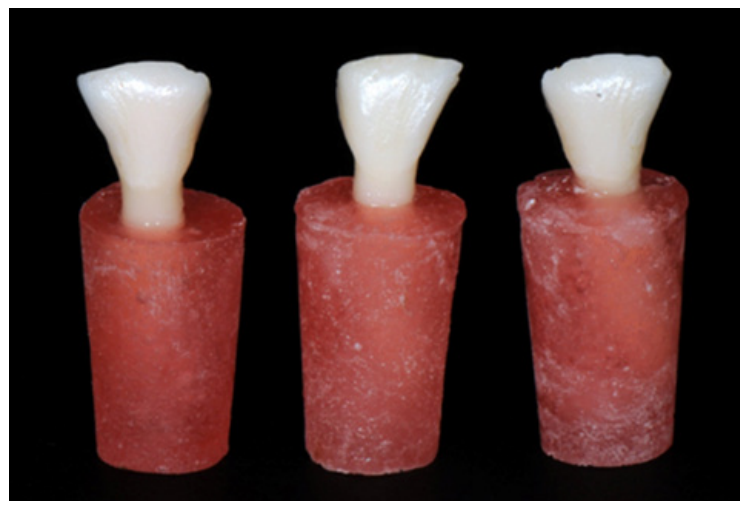

Figure $\mathbf{2}$ Teeth individually secured in cold resin (Leocryl; Leone, Sesto Fiorentino, Italy).

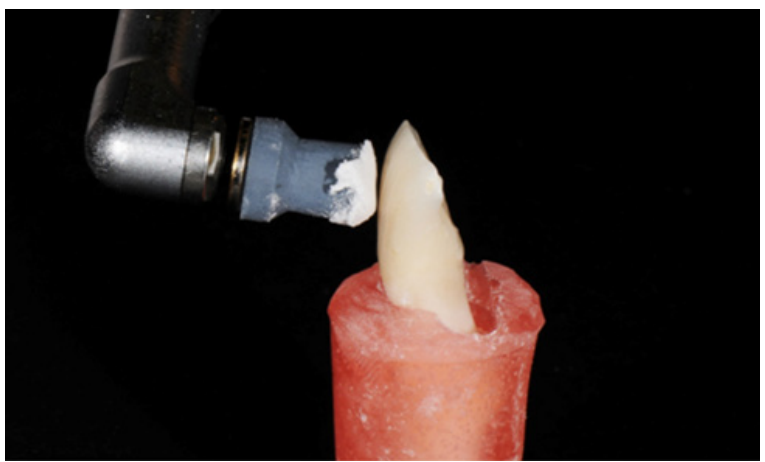

Figure 3 Buccal faces were cleansed for 10 seconds with a mix of water and aluminum oxide (50 micron) with a rubber polishing bur mounted on a contrangle.

1. Kuraray adhesive system (Kuraray Medical, Tokyo, Japan):

a. K-Etchant gel (etching)

b. Kurasper F F-Bond (bonding)

c. Kurasper F Paste (composite cement)

2. 3M adhesive system (Unitek/3M, Monrovia, Calif):

i. Transbond XT etching gel system (etching)

ii. Transbond XT light cure adhesive primer (bonding)

iii. Transbond XT Light cure adhesive paste (composite cement)

All teeth were divided in 4 groups.

\section{Group I: Direct Transbond (DT)}

16 teeth directly bonded with $3 \mathrm{M}$ Transbond materials. Each tooth was etched with $3 \mathrm{M}$ orthophosphoric acid $35 \%$ for 40 seconds, washed and dried; a thin layer of bonding was distributed with a disposable brush. The bonding was cured for 20seconds with a LED lamp (Valo
Ultradent) with a light intensity of $1,000 \mathrm{~mW} / \mathrm{cm}^{2}$. The composite was applied on the bracket base and the same has been positioned in the center of the clinical crown of the tooth. The composite was polymerized with a LED lamp (Valo Ultradent) for 20 seconds from each side of the bracket, ${ }^{26}$ with a $1000 \mathrm{~mW} / \mathrm{cm}^{2}$ light intensity (Figure 4).

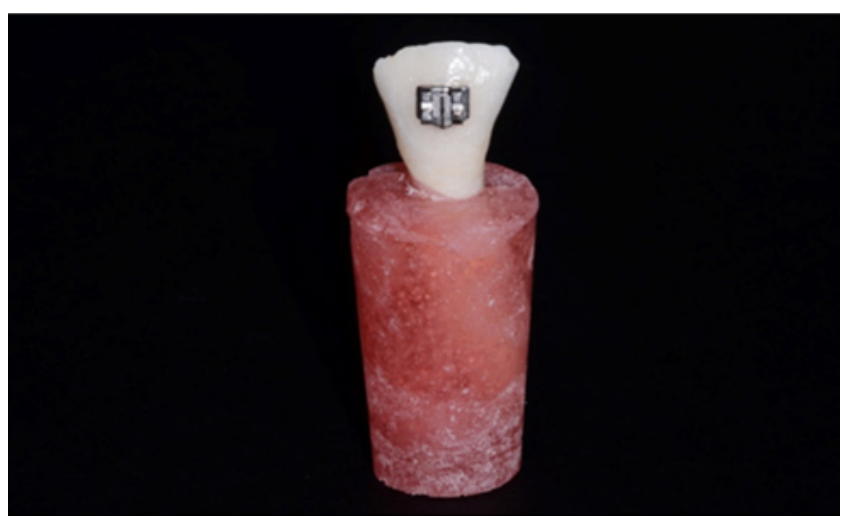

Figure 4 Cow mandibular incisor with a bracket bonded directly.

\section{Group 2: Direct Kurasper (DK)}

16 teeth directly bonded with Kuraray materials (Kuraray Medical Inc. Okayama, Japan). The same protocol performed for group 1 was repeated.

\section{Group 3: Indirect Transbond (IT)}

16 teeth bonded with indirect technique and $3 \mathrm{M}$ materials. In this group, thermo-formed trays were used as transfer, according to the technique described in the article by Cozzani et al. ${ }^{18}$ Brackets were bonded on resin replicas of cow's teeth, produced by a 3D printer (Objet Eden260V Stratasys) as a result of the tooth scan. A 3D scanner was used (3Shape D800) (Figure 5). Two layers of resin separating liquid have been applied (Insulator for acrylics, Leone ${ }^{\circledR}$ ) with a disposable brush on all surfaces of the tooth replicas. Transbond XT composite cement was applied on the basis of each bracket before they were positioned in the center of the clinical crown of the teeth. Excess was removed and composite was polymerized with a LED lamp (Valo Ultradent) for 20seconds from each side of the bracket with a light intensity of $1000 \mathrm{~mW} / \mathrm{cm}^{2}$. Two trays were formed with a positive-pressure thermos-former (Biostar- Scheu Dental): a first one, more flexible (soft copyplast $0.5 \mathrm{~mm}$-Scheu Dental), which could contain the brackets and at the same time be easily removed and a harder one (duran hard $0.6 \mathrm{~mm}$ - Scheu Dental) that could remain outside for secure positioning reproducibility (Figure 6). The thermoformed transfer trays, now containing brackets, were detached from the resin replicas. The brackets inside the masks were cleaned with acetone (Hydrol). Once the acetone evaporated, Transbond adhesive primer was applied to all brackets. Each tooth was etched with $3 \mathrm{M}$ orthophosphoric acid $35 \%$ for 30 seconds. The transfer trays were positioned on the tooth and pressed to improve the contact between the bracket and the tooth surface during the polymerization; this was performed with a LED lamp (Valo, Ultradent) for 20 seconds from each side of the bracket with a light intensity of $1000 \mathrm{~mW} / \mathrm{cm}^{2}$. Transfer trays were removed with a probe, trying not to detach the bracket.

\section{Group 4: Indirect Kurasper (IK)}

16 teeth bonded with indirect bonding technique and Kuraray adhesive materials. The same protocol used for Group 3 was repeated. 
After bonding, all samples were maintained in distilled water for 24 hours. ${ }^{23}$ at room temperature; they were then tested for shear bond strength with a universal testing machine (Model 4301; Instron Corp., Canton, Massachusetts, USA) (Figure 7) with a load cell of $5 \mathrm{KN}$. The samples were fixed in the lower part of the machine in such a way that the base of the bracket was parallel to the direction of the separation force (Figure 8). The samples have undergone traction in gingival direction at a speed of $1 \mathrm{~mm} /$ minute, in agreement with previous studies. ${ }^{25-32}$

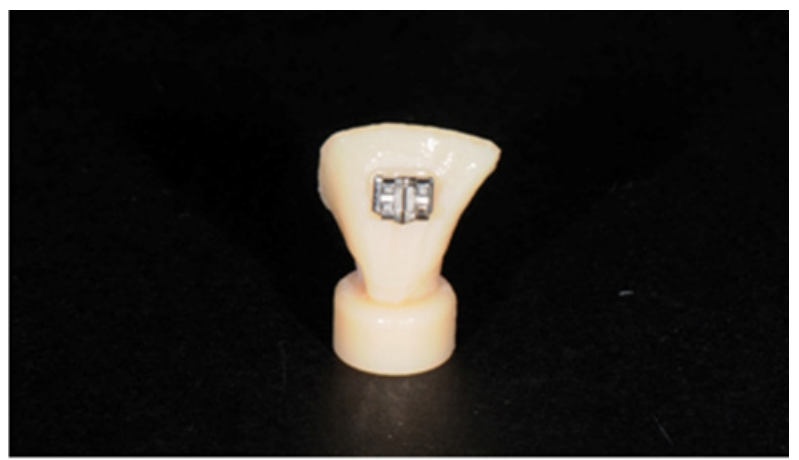

Figure 5 Resin replica with the bracket bonded.

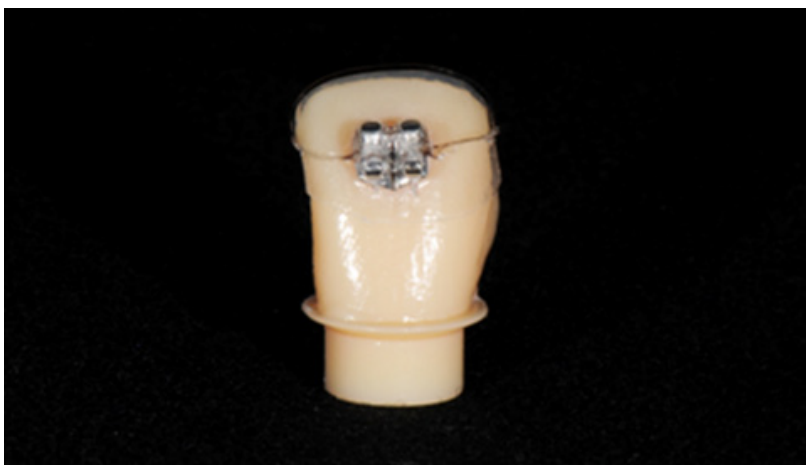

Figure 6 Resin replica with bracket and two thermo-formed trays.

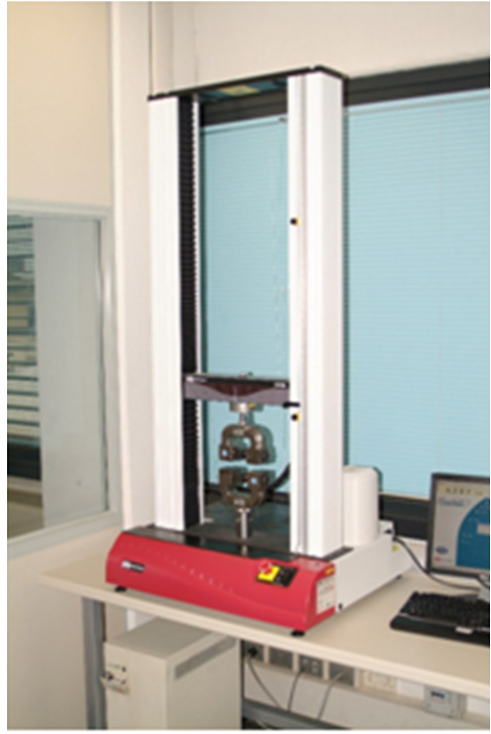

Figure 7 Instron universal testing machine.

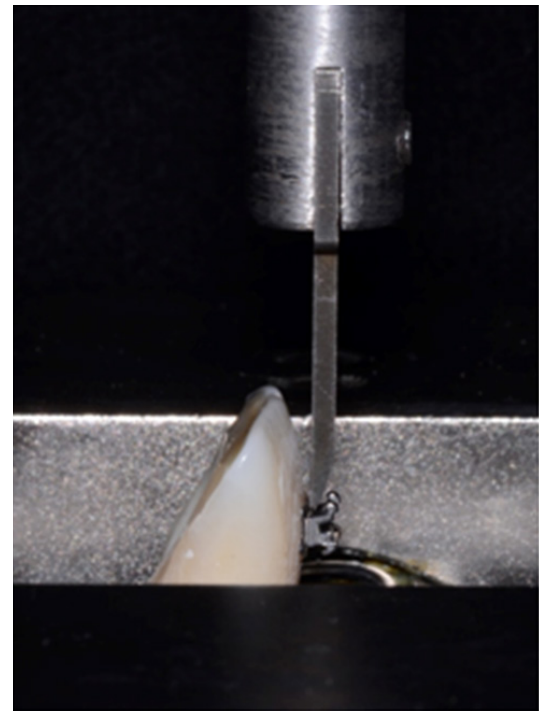

Figure 8 Positioning for shear bond strength test.

\section{ARI}

After breakage of the adhesive bond, the surface of treated teeth was examined with an optical microscope at 10 magnifications (Nikon SMZ800) to determine the amount of composite cement remained on the enamel. The ARI score described by Artun \& Bergland. ${ }^{33}$ was used: it measures bond failure by assessing the amount of adhesive left on the tooth as follows: 0 , no adhesive remaining; 1 , less than half of the adhesive remaining; 2, more than half of the adhesive remaining; 3 , all adhesive remaining.

\section{Statistical analysis}

Two-way analysis of variance (ANOVA) was used to determine the significant differences among the samples consisting of different materials and subjected to various bonding methods, and combinations thereof. Chi-squared analysis was used to test the significance of differences in the distributions of the ARI scores. Results were analyzed with a statistical software program STATA 12 (Stata Corp, College Station, Tex) and the level of significance was set at $p \leq 0.05$. All values were reported in Newton and later converted into Megapascal as the ratio of Newton/ bracket surface.

\section{Results}

\section{Shear bond strength test}

The two-way ANOVA test showed that there are no significant differences for what concerns the bonding technique $(p=0.9606)$, the composite cement used $(\mathrm{p}=0.1653)$ and the interaction between these two variables $(p=0.6077)$. It is showed therefore, that there are no differences among the four analyzed groups in shear bond strength.

\section{ARI index}

The Chi-square test showed that there is no statistically significant difference between the separation surfaces in the four groups $(\mathrm{p}=0.185)$. The same operator, after one week, repeated ARI scores of 10 random selected teeth, obtaining a $100 \%$ consistency with previous values assigned (Figures 9-14 \& Table 1). 


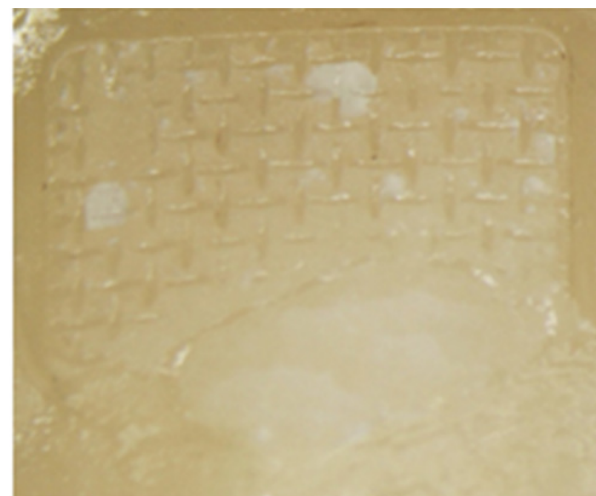

Figure 9 ARI index 2 (DTI).

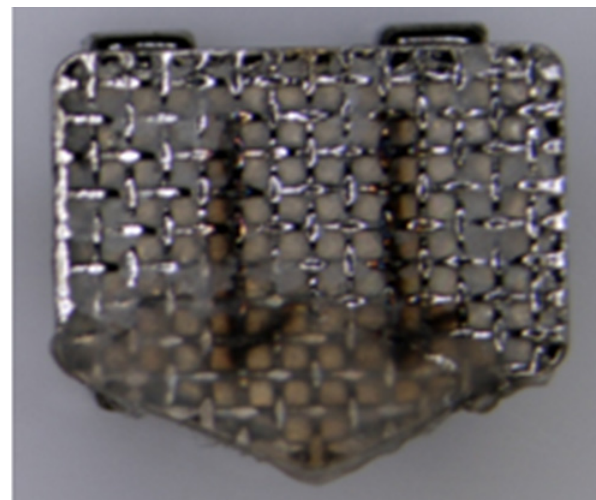

Figure IO ARI index 2 (bracket DTI).

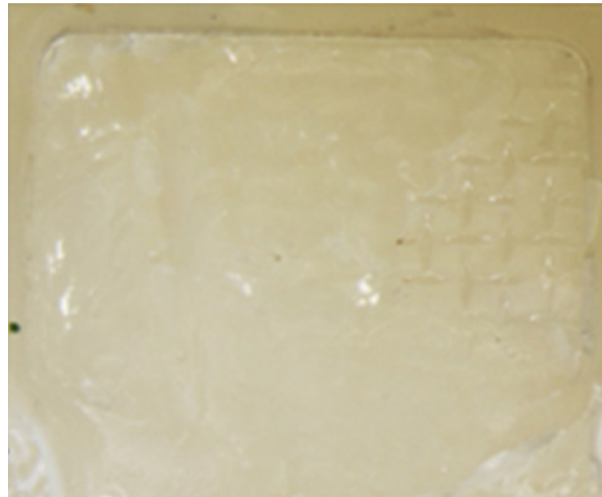

Figure I I ARI index I (IKII).

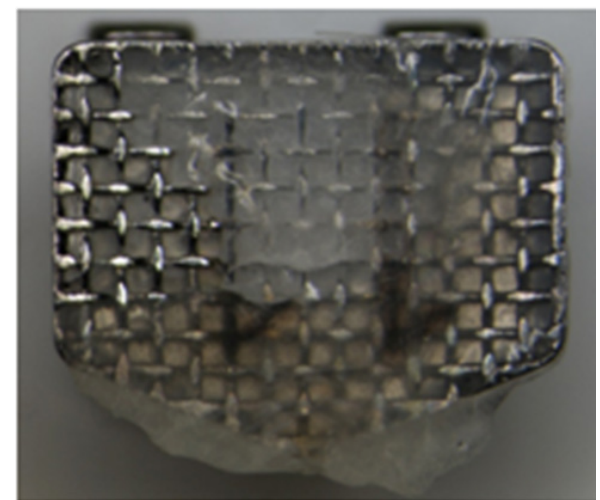

Figure I 2 ARI index I (bracket IKII).

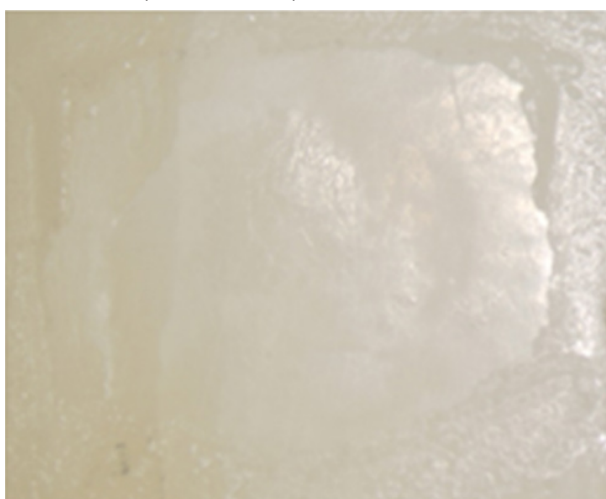

Figure I 3 ARI index 0 (DT8).

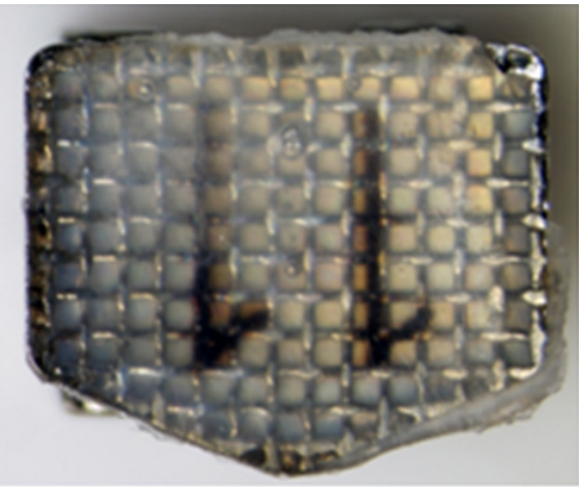

Figure I 4 ARI index 0 (bracket DT8).

Table I Description of ARI index and shear bond strength values in the four groups

\begin{tabular}{|c|c|c|c|c|c|c|c|}
\hline \multicolumn{4}{|c|}{ Direct bonding } & \multicolumn{4}{|l|}{ Indirect bonding } \\
\hline \multicolumn{2}{|c|}{ Proof resistance $\left(\mathrm{N} / \mathrm{mm}^{2}\right)$} & \multirow{2}{*}{$\begin{array}{l}\text { ARI } \\
2\end{array}$} & \multirow{2}{*}{$\begin{array}{l}\text { Resistance }\left(\mathbf{N} / \mathbf{m m}^{2}\right) \\
21,17\end{array}$} & \multirow{2}{*}{$\begin{array}{l}\text { Resistance }\left(\mathbf{N} / \mathbf{m m}^{2}\right) \\
8,39\end{array}$} & \multirow{2}{*}{$\begin{array}{l}\text { ARI } \\
\mathrm{I}\end{array}$} & \multirow{2}{*}{$\begin{array}{l}\text { Resistance }\left(\mathbf{N} / \mathbf{m m}^{2}\right) \\
22,99\end{array}$} & \multirow{2}{*}{$\begin{array}{l}\text { AR } \\
2\end{array}$} \\
\hline I & $|7,5|$ & & & & & & \\
\hline 2 & 17,94 & 2 & 17,7 & 12,43 & I & 24,99 & 2 \\
\hline 4 & 19,39 & 0 & 24,29 & 14,04 & 2 & 9,3 & I \\
\hline 5 & 27,07 & 1 & 9,96 & 11,6 & 0 & 17,9 & I \\
\hline 6 & $1 \mathrm{I}, 83$ & 2 & 17,42 & 22,12 & I & $|8,6|$ & I \\
\hline
\end{tabular}


Table Continued...

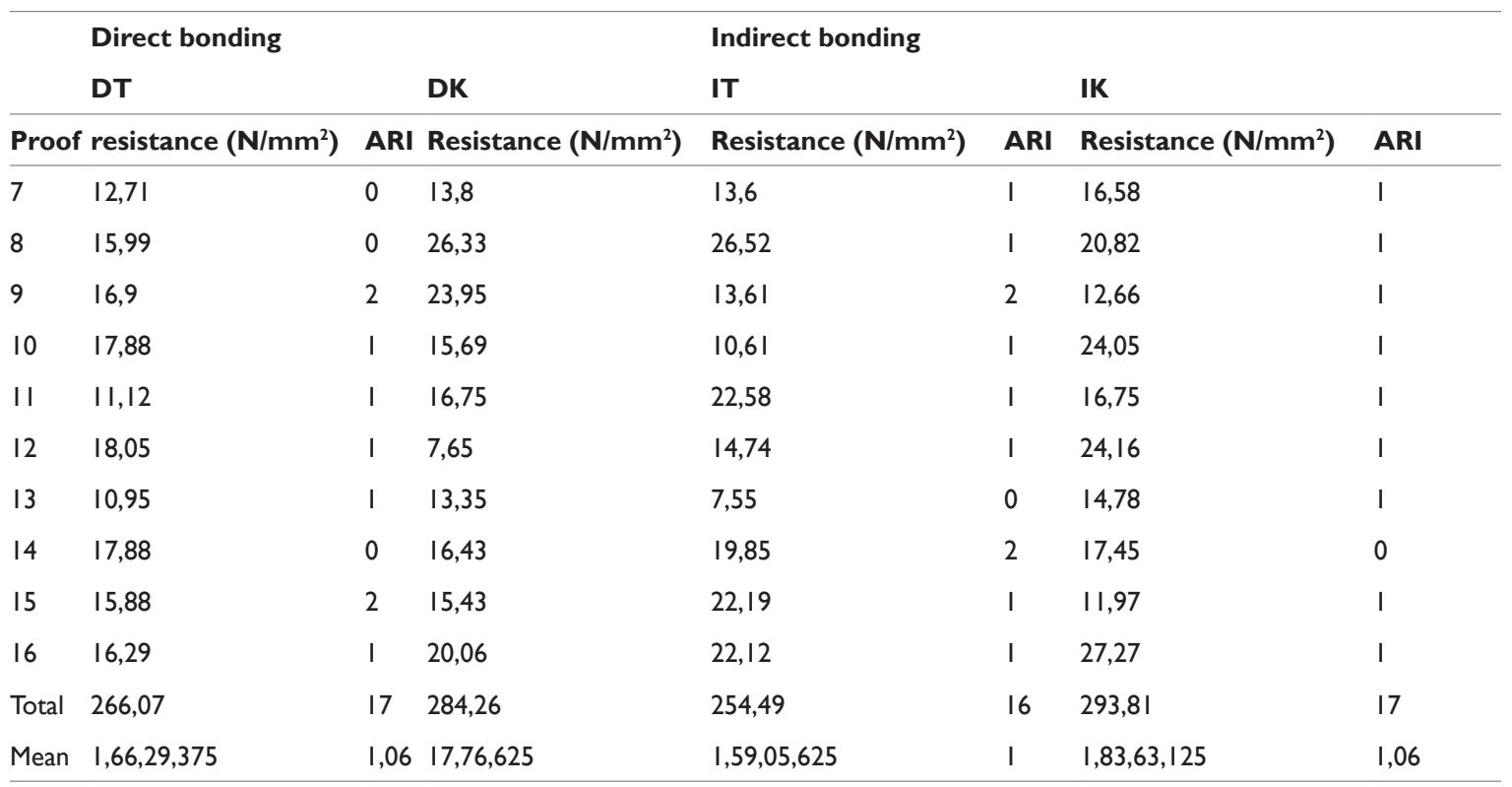

\section{Discussion}

We chose to use cow's teeth despite the ideal material for this study were human teeth because these are judged from the literature as a viable alternative. ${ }^{34,35}$ Cow's incisors were preferred for their vestibular flat surface, which has allowed a greater uniformity of the adhesive cement layer thickness and therefore the elimination of a possible variable in the evaluation of adhesion strength. Previous studies have obtained inferior adhesion values with cow's teeth when compared to human teeth. ${ }^{27}$ Thermoformed trays have been preferred to other techniques because they have a more uniform thickness and are more predictable compared to other methods currently in use. ${ }^{12}$ The quality of bracket adhesion is an important parameter for a successful orthodontic treatment. Reynolds. ${ }^{36}$ suggests that the strength of a minimum bond to obtain a satisfactory result for most of the clinical orthodontic needs is 6-8 MPa; these values are considered sufficient to withstand mastication and orthodontic forces. In our study the adhesion values are higher but were performed under standard laboratory conditions and thus need to be considered carefully in terms of their clinical relevance. The evaluation of adhesion strength was performed 24 hours after polymerization because previous studies have shown that the adhesive bonds are greater: 24 hours is considered the beginning of the stable phase. ${ }^{37,38}$ The ARI index showed that in both techniques and with both cements there are no failures of the adhesive bond which exclusively involve the cement-bracket interface, in agreement with previous studies. ${ }^{37-39}$ The presence of less adhesive on the tooth surface thus indicates a failure of the bonding at the enamel-cement interface; this from a clinical point of view may be preferable because it facilitates the debonding phase. ${ }^{37}$ Although there are no statistically significant differences in the ARI scores, Kuraray cement presents lower values than Transbond both in direct and indirect technique. Furthermore, from the analysis of the detachment surfaces at the optical microscope, it can be noted that the areas surrounding the bracket surfaces look different, depending on the cement that has been used and not on the technique. In fact, teeth bonded with KURASPER cement, show a greater overflow than those bonded with Transbond. The overflows, however, are not to be assigned to the ARI index, which only refers to bracket surfaces. It is assumed that this excess of material is due to the greater density of the Kurasper primers that, when cured, creates thickness. This, however, could be an advantage in the indirect technique as the cement is already polymerized, and only the primer is added: Kurasper detachment values with indirect technique (even if the result is not significant) are the highest of the four groups.

\section{Conclusion}

The resin cements; Kurasper and Transbond have the same shear bond strength and failure sites with orthodontic brackets bonded to bovine enamel either or indirect technique.

\section{Acknowledgments}

We thank Leone, Kuraray, and 3M Unitek for providing the material tested in this study; we also thank Gabriele Scomegna and Elia Ladani (Leone) for their excellent technical assistance and special thank you to Allegra Comba for her support in the data analysis.

\section{Conflicts of interest}

The authors declare that there is no conflict of interest.

\section{Funding}

None.

\section{References}

1. Silverman E, Cohen M, Gianelly AA, et al. A universal direct bonding system for both metal and plastic brackets. Am J Orthod. 1972;62(3):236-244.

2. Silverman E, Cohen M. A report on a major improvement in the indirect bonding technique. J Clin Orthod. 1975;9(5):270-276.

3. Dalessandri D, Dalessandri M, Bonetti S, et al. Effectiveness of an indirect bonding technique in reducing plaque accumulation around braces. Angle Orthod. 2012;82(2):313-318.

4. Zachrisson B, Brobakkeen B. Clinical comparison of direct versus indirect bonding, with different bracket types adhesives. Am J Orthod. 1978;74(1):62-78. 
5. Aguirre MJ, King GJ, Waldron JM. Assessment of bracket placement and bond strength when comparing direct bonding to indirect bonding techniques. Am J Orthod Dentofacial Orthop. 1982;82(4):269-276.

6. Kalange JT. Indirect bonding: a comprehensive review of the advantages. World J Orthod. 2004;5(4):301-307.

7. Koo B, Chung C, Vanarsdall R. Comparison of accuracy of bracket placement between direct and indirect bonding techniques. Am J Orthod Dentofacial Orthop. 1999;116(3):346-351.

8. Sondhi A. Efficient and effective indirect bonding. Am J Orthod Dentofacial Orthop. 1999;115(4):352-359.

9. Thiyagarajah S, Spary DJ, Rock WP. A clinical comparison of bond failures in association with direct and indirect bonding. J Orthod. 2006;33(3):198-204.

10. Daub J, Berzins DW, Linn BJ, et al. Bond strength of direct and indirect bonded brackets after termocycling. Angle Orthod. 76(2):295-300.

11. White LW. A new and improved indirect bonding technique. J Clin Orthod. 1999;33(1):17-23.

12. Fortini A, Giuntoli F, Franchi L. A simplified indirect bonding technique. $J$ Clin Orthod. 2007;41(11):680-683.

13. Hoge TM, Dhopatkar AA, Rock WP, et al. The Burton approach to indirect bonding. J Orthod. 2001;28(4):267-270.

14. Cozzani M, Menini A, Bertelli A. Etching masks for precise indirect bonding. J Clin Orthod. 2010;44(5):326-330.

15. Kalange JT, Thomas RG. Indirect bonding: a comprehensive review of the literature. Semin Orthod. 2007;13(1):3-10.

16. Sinha PK, Nanda RS, Ghosh J. A thermal-cured, fluoride-releasing indirect bonding system. J Clin Orthod. 1995;29(2):97-100.

17. Sondhi A. Efficient and effective indirect bonding. Am J Orthod Dentofacial Orthop. 1999;115(4):352-359.

18. Milne JW, Andreasen GF, Jakobsen JR. Bond strength comparison: A simplified indirect technique versus direct placement of brackets. Am J Orthod Dentofacial Orthop. 1989;96(1):8-15.

19. Linn BJ, Berzins DW, Dhuru VB, et al. A comparison of bond strength between direct-and indirect-bonding methods. Angle Orthod. 2006;76(2):289-294

20. Yi GK, Dumm WJ, Taloumis LJ. Shear bond strength comparison between direct and indirect bonded orthodontic brackets. Am J Orthod Dentofacial Orthop. 2003;124(5):577-581.

21. Menini A, Cozzani M, Sfondrini MF, et al. A 15-month evaluation of bond failures of orthodontic brackets bonded with direct versus indirect bonding technique: a clinical trial. Prog Orthod. 2014;15:70.

22. Flores T, Mayoral JR, Giner L, et al. Comparison of enamel-bracket bond strength using direct- and indirect-bonding techniques with a selfetching ion releasing S-PRG filler. Dent Mater J. 2015;34(1):41-47.

23. James J W, Miller BH, English JD, et al. Effects of high speed curing devices on shear bond strength and microleakage of orthodontic brackets. Am J Orthod Dentofacial Orthop. 2003;123(5):555-561.
24. Scribante A, Cacciafesta V, Sfondrini MF. Effect of various adhesive systems on the shear bond strenght of fiber-reinforced composite. Am J Orthod Dentofacial Orthop. 2006;130(2):224-227.

25. Jobalia SB, Valente RM, de Rijk WG, et al. Bond strength of visible light-cured glass ionomer orthodontic cement. Am J Orthod Dentofacial Orthop. 1997;112(2):205-208.

26. Messersmith ML, Devine SM, Zionic AE. Effects of tooth surface preparation on the shear bond strength of resin-modified glass ionomer cements. J Clin Orthod. 1997;31:503-509.

27. Oesterle LJ, Shellart WC, Belanger GK. The use of bovine enamel in bonding studies. Am J Orthod Dentofacial Orthop. 1998;114(5):514-519.

28. Millett DT, Cattanach D, Mc Fadzean R, et al. Laboratory evaluation of a compomer and a resin-modified glass ionomer cement for orthodontic bonding. Angle Orthod. 1999;69(1):58-64.

29. Haydar B, Sarikaya S, Cehreli Z. Comparison of shear bond strength of three bonding agents with metal and ceramic brackets. Angle Orthod. 1999;69(5):457-462.

30. Shammaa I, Ngan P, Kim H, et al. Comparison of bracket debonding force between two conventional resin adhesives and a resin-reinforced glass ionomer cement: an in vitro and in vivo study. Angle Orthod. 1999;69(5):463-469.

31. Cacciafesta V, Sfondrini MF, Baluga L, et al. Use of a self-etching primer in combination with a resin-modified glass ionomer: effect of water and saliva contamination on shear bond strength. Am J Orthod and Dentofacial Orthop. 2003;124(4):420-426.

32. Cacciafesta V, Sfondrini MF, De Angelis M, et al. Effect of water and saliva contamination on shear bond strength of brackets bonded with conventional, hydrophilic, and self-etching primers. Am J Orthod and Dentofacial Orthop. 2003;123(6):633-640.

33. Artun J, Bergland S. Clinical trials with crystal growth conditioning as an alternative to acid-etch enamel pretreatment. Am J Orthod. 1984;85(4):333-340.

34. Nakamichi I, Iwaku M, Fusayama T. Bovine teeth as possible substitutes in the adhesion test. $J$ Dent Res. 1983;62(10):1076-1081.

35. Fowler CS, Swartz ML, Moore Bk, et al. Influence of selected variables on adhesion testing. Dent Mater. 1992;8(4):265-269.

36. Reynolds IR. A review of direct orthodontic bonding. Br J Orthod. $1975 ; 2(3): 171-178$

37. Yamamoto A, Yoshida T, Tsubota K, et al. Orthodontic bracket bonding enamel bond strength vs time. Am J Orthod Dentofacial Orthop. 2006;130(4):435.e1-435.e6.

38. Trites B, Foley TF, Banting D. Bond strenght comparison of 2 self etching primers over a 3 month storage period. Am J Orthod Dentofacial Orthop. 2004;126(6):709-716.

39. Minick G, Oesterle LJ, Newman SM, et al. Bracket bond strength of new adhesive systems. Am J Orthod Dentofacial Orthop. 2009;135(6):771-776. 